\title{
A comparison of three canopy interception models for a leafless mixed deciduous forest stand in the eastern United States
}

Article

Published Version

Klingaman, N. P., Levia, D. F. and Frost, E. E. (2007) A comparison of three canopy interception models for a leafless mixed deciduous forest stand in the eastern United States. Journal of Hydrometeorology, 8 (4). pp. 825-836. ISSN 15257541 doi: https://doi.org/10.1175/JHM564.1 Available at https://centaur.reading.ac.uk/7242/

It is advisable to refer to the publisher's version if you intend to cite from the work. See Guidance on citing.

To link to this article DOI: http://dx.doi.org/10.1175/JHM564.1

Publisher: American Meteorological Society

All outputs in CentAUR are protected by Intellectual Property Rights law, including copyright law. Copyright and IPR is retained by the creators or other copyright holders. Terms and conditions for use of this material are defined in the End User Agreement.

www.reading.ac.uk/centaur 
Central Archive at the University of Reading

Reading's research outputs online 


\title{
A Comparison of Three Canopy Interception Models for a Leafless Mixed Deciduous Forest Stand in the Eastern United States
}

\author{
NichOlas P. KLINGAMAN* \\ Center for Climatic Research, University of Delaware, Newark, Delaware \\ DELPHIS F. LEVIA \\ Center for Climatic Research, and Department of Geography, University of Delaware, Newark, Delaware \\ ETHAN E. Frost \\ Department of Geography, University of Delaware, Newark, Delaware
}

(Manuscript received 2 March 2006, in final form 31 July 2006)

\begin{abstract}
Canopy interception of incident precipitation is a critical component of the forest water balance during each of the four seasons. Models have been developed to predict precipitation interception from standard meteorological variables because of acknowledged difficulty in extrapolating direct measurements of interception loss from forest to forest. No known study has compared and validated canopy interception models for a leafless deciduous forest stand in the eastern United States. Interception measurements from an experimental plot in a leafless deciduous forest in northeastern Maryland $\left(39^{\circ} 42^{\prime} \mathrm{N}, 75^{\circ} 50^{\prime} \mathrm{W}\right)$ for 11 rainstorms in winter and early spring 2004/05 were compared to predictions from three models. The Mulder model maintains a moist canopy between storms. The Gash model requires few input variables and is formulated for a sparse canopy. The WiMo model optimizes the canopy storage capacity for the maximum wind speed during each storm. All models showed marked underestimates and overestimates for individual storms when the measured ratio of interception to gross precipitation was far more or less, respectively, than the specified fraction of canopy cover. The models predicted the percentage of total gross precipitation $\left(P_{G}\right)$ intercepted to within the probable standard error $(8.1 \%)$ of the measured value: the Mulder model overestimated the measured value by $0.1 \%$ of $P_{G}$; the WiMo model underestimated by $0.6 \%$ of $P_{G}$; and the Gash model underestimated by $1.1 \%$ of $P_{G}$. The WiMo model's advantage over the Gash model indicates that the canopy storage capacity increases logarithmically with the maximum wind speed. This study has demonstrated that dormant-season precipitation interception in a leafless deciduous forest may be satisfactorily predicted by existing canopy interception models.
\end{abstract}

\section{Introduction}

The amount of precipitation intercepted and subsequently evaporated from a forest canopy is considerable, accounting for $29 \%$ of the incident precipitation at Plynlimon Forest, United Kingdom (Calder 1990).

\footnotetext{
* Current affiliation: NCAS Climate and Walker Institute, Department of Meteorology, University of Reading, Reading, Berkshire, United Kingdom.

Corresponding author address: Delphis F. Levia, Department of Geography, University of Delaware, Newark, DE 19716-2514. E-mail: dlevia@udel.edu
}

Canopy interception is a critical component of a forest's water budget, affecting the amount of water available to the understory and soil. The structural characteristics of the forest canopy reduce and spatially redistribute the overall water input to the underlying area (Lloyd and Marques 1988; Herwitz and Slye 1995; Loescher et al. 2002; Abrahams et al. 2003). Canopy structure has been documented to be a key control on the subcanopy water flux, affecting mineral and trace-gas fluxes, surface runoff, and erosion (Whelan and Anderson 1996; Levia and Frost 2003).

The amount of precipitation lost to canopy interception and evaporation is important in determining the water balance of a forested area (Calder 1976, 1977;

DOI: $10.1175 / J H M 564.1$

(C) 2007 American Meteorological Society 
Stewart 1977; Dolman 1987). Many forest canopies are highly coupled to the overlying atmosphere, which enhances moisture exchange; a moist canopy will readily evaporate water into the surrounding air (Rutter 1967; Stewart 1978; Harwood et al. 1999). Several recent studies have suggested that certain canopies, particularly those in tropical climates, may be decoupled to the atmospheric boundary layer (e.g., Derbyshire 1999; Kruijt et al. 2000; Delage et al. 2002). The precise mechanism behind this decoupling is still unclear, as is its applicability to canopies other than those in the above studies. Since interception loss varies with species (Lankreijer et al. 1993; Liu 1998; Wei et al. 2005), accurate measurements can aid predictions of the consequences of land-cover changes. Tree growth, streamflow, groundwater recharge, and water stress are closely related to evaporation, which is in turn strongly correlated to the canopy storage capacity (Halldin et al. 1984).

While one can use throughfall and stemflow measurements to calculate interception loss, this requires frequent data collection and offers few opportunities to extrapolate results to other species or locations. To create more applicable formulas, researchers have constructed dynamic, analytic, and numerical models of interception loss. Rutter et al. (1971) was among the first to derive an interception-loss model, which was based on observations of a Corsican pine (Pinus nigra) stand. The Rutter et al. (1971) model was later generalized and provided accurate interception estimates for two coniferus (Douglas fir and Norway spruce) and three hardwood (one hornbeam and two oak) stands (Rutter et al. 1975). Domingo et al. (1998) found that the Rutter model's estimates of interception agreed with measured values for several semiarid species. While a significant advance, the Rutter model requires a substantial number of input fields, making it difficult to use with routine meteorological data.

Several models developed more recently have overcome the limitations of the Rutter model. This study compares the results from three such canopy interception models against measured interception for a leafless deciduous stand in the mid-Atlantic region of the United States. The three models used are the Mulder (1985) model, the Gash et al. (1995) model, and the WiMo model of Hörmann et al. (1996). The Gash et al. (1995) model is an updated version of the Gash (1979) model that has been reformulated for sparse canopies. By comparing measured and modeled interception, this study will determine the degree to which each model may be generalized to leafless deciduous stands in a temperate winter climate.

Many studies have compared the performance of the
Mulder (1985) model and the older Gash (1979) model. Lankreijer et al. (1993) ascertained that both models overestimated interception for a deciduous forest in the Netherlands and a coniferous forest in France. Dolman (1987) compared these models for an oak forest in the Netherlands and found that the Mulder model overestimated interception relative to both the Gash (1979) model and measured values. Hutjes et al. (1990) concluded that both models accurately predicted interception for an evergreen forest in the Ivory Coast. Liu (2001) compared the Liu (1997) model against the Gash (1979) and Rutter models. The Liu model performed favorably in the more than 20 canopies considered, yet required fewer input variables and contained simpler formulas than either the Gash or Rutter model. The WiMo model has received relatively little attention in the literature and has seldom been compared with other interception models. Few studies have compared interception models against measurements taken in a deciduous stand in the leafless season. The canopy intercepts a far lower fraction of the incident precipitation during the leafless season, yet interception in this season is still a critical component of the water balance. Therefore, whether existing interception models can provide accurate predictions during the leafless season is of importance.

\section{Study area}

The experimental forest plot $\left(800 \mathrm{~m}^{2}\right)$ was located in the Fair Hill Natural Resource Management Area in Fair Hill, Maryland $\left(39^{\circ} 42^{\prime} \mathrm{N}, 75^{\circ} 50^{\prime} \mathrm{W}\right)$ at an elevation of $72 \mathrm{~m}$ above sea level (Fig. 1). The rectangular study plot was nearly level with a stand density of 225 trees $\mathrm{ha}^{-1}$ and a stand basal area of $36.8 \mathrm{~m}^{2} \mathrm{ha}^{-1}$, indicating that there were relatively few but large trees within the study plot. The canopy trees had a mean diameter at breast height (dbh, $1.37 \mathrm{~m}$ above ground level) of 40.8 $\mathrm{cm}$ and a mean height of $27.8 \mathrm{~m}$. The mean bark thickness of the canopy trees was $7.0 \mathrm{~mm}$. Fagus grandifolia Ehrh. (American beech) was the most common tree species within the plot, accounting for approximately $50 \%$ of the canopy trees. Liriodendron tulipifera $\mathrm{L}$. (yellow poplar) was the second most common species, constituting approximately $25 \%$ of the canopy trees. The remaining $25 \%$ of canopy trees were composed of Quercus velutina Lam. (black oak), Acer rubrum L. (red maple), and Acer saccharinum L. (silver maple).

The Fair Hill Natural Resource Management Area is close to the Atlantic coast and experiences a temperate climate. The mean annual precipitation is $1221.5 \mathrm{~mm}$ and precipitation does not vary greatly with season. 


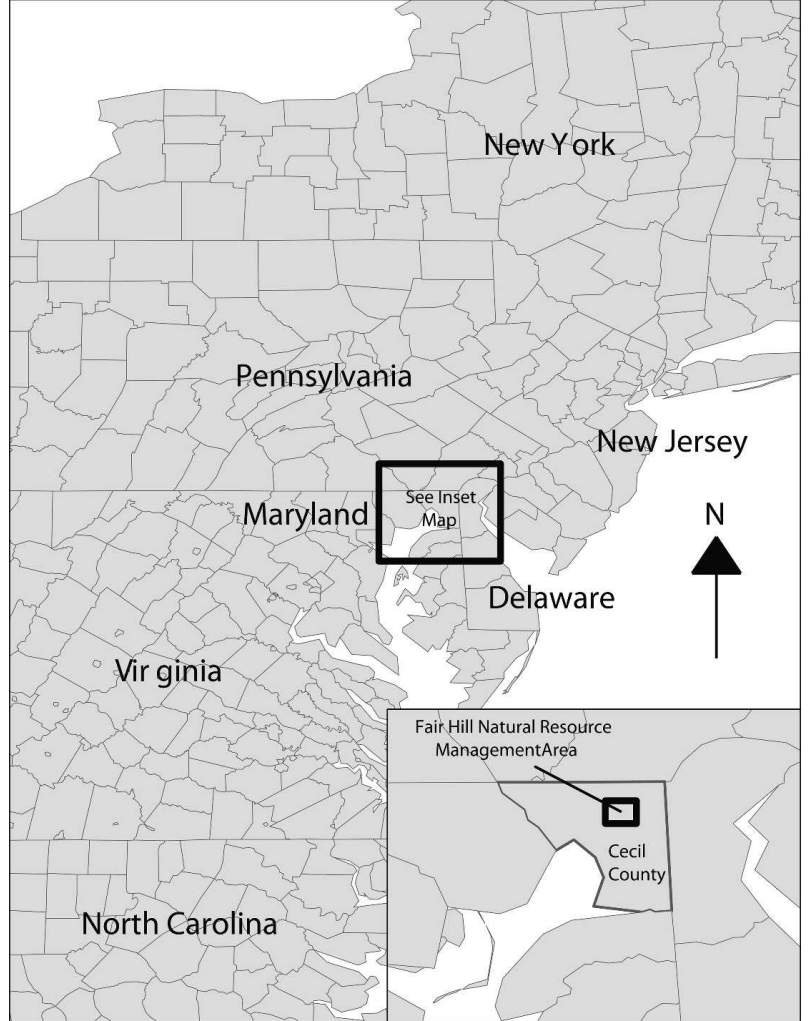

$0 \quad 60 \quad 120180240$ Kilometers

FIG. 1. A map showing the location of Fair Hill Natural Resource Management Area in the context of the mid-Atlantic United States.

Summer is the wettest season (324.1 mm total for June, July, and August) and winter the driest (274.1 mm for December, January, and February). Snowfall occurs almost exclusively in winter, and the annual total (350.5-mm depth on average) is often dominated by only a few storms. The mean January (July) air temperature is $-0.6^{\circ} \mathrm{C}\left(24.6^{\circ} \mathrm{C}\right)$. The growing season averages 191 days in April through October.

\section{Materials and methods}

\section{a. Throughfall and stemflow}

Throughfall and stemflow measurements were manually collected approximately two hours after each of 11 rainstorms from 1 December 2004 until 30 April 2005 (Table 1). In the text, we will refer to storms by the date on which they began. The storms cover a wide spectrum-from a warm, driving rain (23 December) to a cold drizzle (7 January) to an intense spring storm (1 April) - and so this dataset may be considered repre- sentative of the rainstorms that occur in this region during the leafless season.

Thirty funnel-type throughfall gauges were positioned within the plot and one tree was fitted with a stemflow collar. Eighteen of the gauges had an orifice diameter of $17.8 \mathrm{~cm}$, while the remaining 12 gauges had an orifice diameter of $12.4 \mathrm{~cm}$. The gauges were randomly redistributed throughout the plot after each storm to reduce the probable standard error of the throughfall measurements (Lloyd and Marques 1988). The stemflow collar was placed on a representative $F$. grandifolia with a similar branching architecture to the others in the plot and a dbh of $39.8 \mathrm{~cm}$, close to the mean stand dbh. The two stemflow collection bins overflowed during two storms: 11 January and 22 March. Stemflow for these storms was estimated with a regression equation comparing gross precipitation $\left(P_{g}\right)$ and stemflow $\left(r^{2}=0.977, p<0.01\right)$ for the other nine events.

\section{b. Meteorological conditions}

A clearing about $800 \mathrm{~m}$ to the east of the plot housed a meteorological station equipped with a vibrating-wire rain gauge (Geonor A/S; Oslo, Norway) that measured $P_{g}$ every hour. An alter-type wind shield around the rain gauge reduced collection errors from wind-driven precipitation. Temperature, wind speed and direction, relative humidity, incident radiation, and barometric pressure were measured every $5 \mathrm{~min}$.

\section{c. Wet-canopy evaporation}

In this and all subsequent equations, a horizontal line over a quantity $X$ (i.e., $\bar{X}$ ) denotes a time average of that quantity. Values for all parameters and constants are given in Table 2. We used the Penman-Monteith equation given in Lankreijer et al. (1993) to calculate the wet-canopy evaporation as

$$
E^{\prime}=\left[D \bar{R}_{n}+\rho_{a} C_{p}\left(e_{s}-e_{a}\right) / r_{a}\right] /[(D+\gamma) \lambda],
$$

where $E^{\prime}$ is the evaporation rate $\left(\mathrm{kg} \mathrm{m}^{-2} \mathrm{~s}^{-1}\right), D$ is the slope of the saturated water vapor pressure curve at the hourly mean air temperature $(\bar{T})\left(\mathrm{Pa} \mathrm{K}^{-1}\right), \bar{R}_{n}$ is the hourly mean net radiation $\left(\mathrm{W} \mathrm{m}^{-2}\right), C_{p}$ is the specific heat of the atmosphere at constant pressure $\left(\mathrm{J} \mathrm{kg}^{-1}\right.$ $\left.\mathrm{C}^{-1}\right), e_{s}$ and $e_{a}$ are the saturation and actual vapor pressure $(\mathrm{Pa})$, respectively, $r_{a}$ is the aerodynamic resistance $\left(\mathrm{s} \mathrm{m}^{-1}\right), \gamma$ is the psychrometric constant $\left(\mathrm{Pa} \mathrm{K} \mathrm{K}^{-1}\right)$, and $\lambda$ is the latent heat of vaporization $\left(\mathrm{J} \mathrm{kg}^{-1}\right)$. Here $\bar{R}_{n}$ was estimated from measured shortwave radiation values and longwave radiation calculated from the Angstrom equations. 
TABLE 1. A summary of meteorological conditions during each rainstorm: total precipitation $\left(P_{g}, \mathrm{~mm}\right)$, precipitation rate $\left(\bar{P}^{\prime}\right.$, mm $\left.\mathrm{h}^{-1}\right)$, air temperature $\left(\bar{T},{ }^{\circ} \mathrm{C}\right)$, relative humidity $(\overline{\mathrm{RH}}, \%)$, barometric pressure $\left(\bar{B}_{p}, \mathrm{mb}\right)$, wind speed $\left(\bar{u}, \mathrm{~m} \mathrm{~s}^{-1}\right)$, maximum wind speed $\left(u_{\max }, \mathrm{m} \mathrm{s}^{-1}\right)$, and wet-canopy evaporation $\left(\bar{E}^{\prime}, \mathrm{mm} \mathrm{hour}^{-1}\right)$. All values except for total precipitation and maximum wind speed are storm-averaged from 5-min observations.

\begin{tabular}{lccccccrr}
\hline \hline \multicolumn{1}{c}{ Dates } & $P_{g}$ & $\bar{P}^{\prime}$ & $\bar{T}$ & $\overline{\mathrm{RH}}$ & $\bar{B}_{p}$ & $\bar{u}$ & $u_{\max }$ & $\bar{E}$ \\
\hline 7-8 Dec 2004 & 10.9 & 0.5 & 7.9 & 97.2 & 1012.4 & 2.4 & 3.8 & 0.023 \\
9-13 Dec 2004 & 25.6 & 0.3 & 7.0 & 85.6 & 1004.4 & 2.9 & 6.2 & 0.024 \\
23 Dec 2004 & 25.1 & 2.5 & 12.2 & 94.4 & 1009.9 & 5.6 & 7.9 & 0.020 \\
3-6 Jan 2005 & 23.5 & 0.3 & 6.2 & 93.4 & 1019.6 & 2.3 & 6.5 & 0.025 \\
7-8 Jan 2005 & 8.5 & 0.5 & 2.3 & 95.0 & 1025.0 & 1.6 & 3.6 & 0.027 \\
11-14 Jan 2005 & 55.1 & 0.8 & 8.9 & 93.1 & 1019.7 & 3.3 & 11.4 & 0.027 \\
9-10 Feb 2005 & 6.8 & 0.3 & 7.3 & 81.0 & 1008.9 & 2.8 & 5.7 & 0.048 \\
22-23 Mar 2005 & 40.6 & 1.4 & 3.8 & 91.7 & 1014.8 & 3.5 & 8.6 & 0.094 \\
27-28 Mar 2005 & 53.8 & 2.1 & 6.5 & 92.6 & 1008.2 & 4.0 & 9.4 & 0.100 \\
1-3 Apr 2005 & 71.2 & 2.0 & 9.4 & 93.0 & 999.0 & 4.0 & 5.4 & 0.105 \\
6-8 Apr 2005 & 7.9 & 0.3 & 15.1 & 76.8 & 1012.3 & 3.5 & 6.3 & 0.111 \\
\hline
\end{tabular}

The $r_{a}$, term in Eq. (1) has traditionally been approximated as the aerodynamic resistance for momentum

$$
r_{a, M}=\left(k^{2} u\right)^{-1} \ln \left[(z-d) / z_{0, M}\right]^{2},
$$

where $r_{a, M}$ is the aerodynamic resistance for momentum $\left(\mathrm{s} \mathrm{m}^{-1}\right), k$ is the von Kármán constant, $u$ is the wind speed $\left(\mathrm{m} \mathrm{s}^{-1}\right), z$ is the measurement height $(\mathrm{m}), d$ is the zero-plane displacement height $(\mathrm{m})$, and $z_{0, M}$ is the roughness length for momentum (m). Rutter et al. (1975) used this equation to estimate $r_{a}$ for both leafed and leafless canopies. Lankreijer et al. (1993) found that using the aerodynamic resistance for heat $\left(r_{a, H}\right)$ instead of $r_{a, M}$ improved estimates of interception in both the Mulder (1985) and Gash (1979) models for an oak canopy in the Netherlands. Lankreijer et al. (1993) calculated the $r_{a, H}$ as

$$
r_{a, H}=\left(k^{2} u\right)^{-1} \ln \left[(z-d) / z_{0, M}\right] \ln \left[(z-d) / z_{0, H}\right],
$$

where $z_{0, H}$ is the roughness length for heat $(\mathrm{m})$. We believe that using Eq. (3) instead of Eq. (2) to approximate $r_{a}$ in Eq. (1) is appropriate for our leafless mixed deciduous canopy and will improve all three models' results.

Finally, we converted $E^{\prime}$ to a value of millimeters per hour to match our precipitation measurements. The storm-averaged evaporation rate $\left(\bar{E}^{\prime}\right)$ was quite low for the December and January storms because of the low values of incident shortwave radiation during the winter season (Table 1). The average evaporation rate increased rapidly in February and March as more energy became available to evaporate water from the canopy. The seasonal trend in $R_{n}$ accounted for approximately $70 \%$ of the variance in $\bar{E}^{\prime}$. This indicates that the wetcanopy evaporation during these storms depended pri- marily on the seasonal cycle of solar irradiance and not on other meteorological variables (e.g., relative humidity or wind speed). Averaged over 1 December 2004-30 April 2005, $E^{\prime}$ was $0.07 \mathrm{~mm} \mathrm{~h}^{-1}$, which is equivalent to $613 \mathrm{~mm} \mathrm{yr}^{-1}$ or $50 \%$ of the mean annual precipitation at the site.

\section{d. Stand and canopy parameters}

Values for $d, z_{0, M}$, and $z_{0, H}$ were calculated as $0.5 h$ (Rutter et al. 1975), 0.36(h-d) (Thom 1971), and $0.14 z_{0, M}$ (Garratt and Francey 1978), respectively, where $h$ is the mean tree height. We estimated that the measurement height $z$ was several meters above $h$. We assumed that the stand albedo $(\alpha)$ remained constant during the leafless season at the median value found by

\begin{tabular}{|c|c|c|c|}
\hline Parameter & Description & Value & Units \\
\hline$\rho_{a}$ & Atmospheric density & 1.21 & $\mathrm{~kg} \mathrm{~m}^{-3}$ \\
\hline$C_{p}$ & $\begin{array}{l}\text { Specific heat at constant } \\
\text { pressure }\end{array}$ & 1004 & $\mathrm{~J} \mathrm{~kg}^{-1} \mathrm{~K}^{-1}$ \\
\hline$\gamma$ & Psychrometric constant & 64 & $\mathrm{~Pa} \mathrm{~K}^{-1}$ \\
\hline$\lambda$ & $\begin{array}{r}\text { Latent heat of } \\
\text { vaporization }\end{array}$ & $2.45 \times 10^{6}$ & $\mathrm{~J} \mathrm{~kg}^{-1}$ \\
\hline$k$ & von Kármán's constant & 0.41 & \\
\hline$z$ & Measurement height & 30 & $\mathrm{~m}$ \\
\hline$d$ & Zero-plane displacement & 13.9 & $\mathrm{~m}$ \\
\hline$z_{0, H}$ & Roughness length for heat & 0.70 & $\mathrm{~m}$ \\
\hline$z_{0, M}$ & $\begin{array}{l}\text { Roughness length } \\
\text { for momentum }\end{array}$ & 5.00 & $\mathrm{~m}$ \\
\hline$\alpha$ & Albedo & 0.15 & \\
\hline$c_{t}$ & $\begin{array}{l}\text { Coefficient of free } \\
\text { throughfall }\end{array}$ & 0.9 & \\
\hline$S_{c}$ & Canopy storage capacity & 1.48 & $\mathrm{~mm}$ \\
\hline$c_{s}$ & $\begin{array}{l}\text { Fraction of precipitation } \\
\text { diverted to stemflow }\end{array}$ & 0.08 & \\
\hline$S_{t}$ & Trunk storage capacity & 0.09 & $\mathrm{~mm}$ \\
\hline
\end{tabular}

TABLE 2. Values held constant in this study. 
Moore et al. (1996). That study analyzed $3 \mathrm{yr}$ of observations for a temperate deciduous forest and found that $\alpha$ varied between 0.10 and 0.20 during the leafless season.

Following leaf abscission, a Li-Cor LI-2000 Plant Canopy Analyzer measured a plant-area index (PAI) of $1.19 \mathrm{~m}^{2} \mathrm{~m}^{-2}$. The coefficient of free throughfall $\left(c_{t}\right)$ was assumed to equal 0.3 for a canopy in full leaf (Mulder 1985), and thereafter to increase linearly as the PAI decreased throughout the autumn; a hypothetical canopy with a PAI of zero should have a $c_{t}$ of unity. We used a linear regression relating $c_{t}$ to PAI to determine $c_{t}$ for our leafless stand.

A value for the canopy storage capacity $\left(S_{c}\right)$ for a leafless deciduous stand was taken from Halldin et al. (1984). The stand in that study contained a substantial fraction of beech trees and had a mean tree height, basal area, and stand density remarkably similar to our stand. Values for the fraction of precipitation diverted to stemflow $\left(c_{s}\right)$ and trunk storage capacity $\left(S_{t}\right)$ were obtained from Hörmann et al. (1996) for a nonfoliated beech forest. These values agree with those given in Kittredge (1948) for beech. Canopy parameter values obtained from previous work in other leafless forests were deemed to be reasonable based on field observations at the study plot. The effects of our estimations and assumptions will be discussed in section 6 , where a sensitivity analysis will be conducted for each model.

\section{Model descriptions}

\section{a. Common terms}

We define $c$ to be the fraction of the canopy covered, or

$$
c=1-c_{t}
$$

Gash et al. (1995) used this relationship to convert a measured value of canopy cover to a coefficient of free throughfall. Each of the models calculates $E^{\prime}$ as in Eq. (1). The amount of precipitation striking the canopy during each storm is

$$
P_{v}=c P_{g}
$$

For the Gash et al. (1995) and WiMo models, the amount of precipitation diverted to stemflow is

$$
S_{f}=c_{s} P_{g}
$$

for those storms that saturate the canopy. Stemflow is neglected for all storms in the Mulder (1985) model and for storms that do not saturate the canopy in the Gash et al. (1995) and WiMo models.

\section{b. Mulder (1985) model}

Mulder (1985) developed a numerical model (hereafter the "Mulder model") notable both for its use of standard meteorological variables to derive interception loss, as well as its ability to maintain a moist canopy between storms by calculating a running water balance. For each day, separate averages of hourly $R_{n}$ and $E^{\prime}$ are maintained for rainy and dry periods. Rainy periods are defined as those hours when the Geonor gauge recorded more than $0.1 \mathrm{~mm}$ of precipitation. The ability to distinguish between rainy and dry conditions is a key difference between the Mulder model and the Gash and WiMo models.

Precipitation is summed over the day and then evenly divided into small showers of equal duration $\left(t_{\text {shw }}\right)$. The number of showers is defined as the number of rainy periods bounded by at least $2 \mathrm{~h}$ of dry conditions. Showers continuing through the end of the day are considered to have stopped at midnight. Showers beginning in the first (final) two hours of a day are (are not) counted. The model distributes the showers and dry intervals evenly throughout the day. All dry intervals are initially of equal duration $\left(t_{\mathrm{dry}}\right)$. The length of the last dry interval in each day is averaged with the first dry interval in the following day. Half of the averaged dry interval is placed in each day, so that every day effectively begins and ends with a shortened dry interval.

All showers in the same day have a constant hourly precipitation rate, equal to the mean hourly precipitation rate during rainy periods $\left(\bar{P}_{r}^{\prime}\right)$. The mean hourly rate of precipitation striking the canopy is therefore

$$
\bar{P}_{v}^{\prime}=c \bar{P}_{r}^{\prime},
$$

consistent with Eq. (5).

Each shower begins with the canopy in the wettingup phase. The canopy can only become saturated if $\bar{P}_{v}^{\prime}$ is greater than the mean evaporation rate during rainy periods $\left(\bar{E}_{r}^{\prime}\right)$. If this condition is met, the model calculates the time required for the canopy to reach saturation $\left(t_{\mathrm{sat}}\right)$, given the amount of water initially on the canopy $\left(C_{\mathrm{wi}}\right)$ (Table 3). If $t_{\mathrm{sat}}>t_{\mathrm{shw}}$ or if $\bar{P}_{v}^{\prime} \leq \bar{E}_{r}^{\prime}$, the canopy does not become saturated and the total interception for the shower is given by the interception for the wetting-up phase $\left(I_{w}\right) ; C_{\mathrm{wf}}$ represents the amount of water on the canopy at the end of the shower. If the canopy reaches saturation, the canopy spends the remaining time (i.e., $t_{\mathrm{shw}}-t_{\mathrm{sat}}$ ) in the saturation phase. In this case, $C_{\mathrm{wf}}$ is equal to $S_{c}$ and the total interception for the shower is the sum of $I_{w}$ and the interception during the saturation phase $\left(I_{s}\right)$.

After the shower ends, the canopy moves into the drying-out phase. The canopy water at the end of the 
TABLE 3. A comparison of the fundamental equations for each model. The Gash and WiMo models dry out completely after each storm and include a separate term for the "interception" during the drying-out phase. The Mulder model does not account for stemflow.

\begin{tabular}{|c|c|c|c|}
\hline Term & Description & Mulder model & Gash and WiMo models \\
\hline$P_{\text {sat }}$ & Precipitation required to saturate canopy & None & $-\bar{P}^{\prime} S_{c} /\left(c \bar{E}^{\prime}\right) \ln \left(1-\bar{E}^{\prime} / \bar{P}^{\prime}\right)$ \\
\hline$C_{\mathrm{wi}}$ & Canopy water at start of wetting-up phase & & None \\
\hline$t_{\text {sat }}$ & Time required to saturate canopy & $\left(S_{c} / \bar{E}_{r}^{\prime}\right) \ln \left[\left(\bar{P}_{v}^{\prime} S_{c}-C_{\mathrm{wi}} \bar{E}_{r}^{\prime}\right) /\left(\bar{P}_{v}^{\prime} S_{c}-S_{c} \bar{E}_{r}^{\prime}\right)\right]$ & None \\
\hline \multirow[t]{2}{*}{$C_{\mathrm{wf}}$} & Canopy water at end of wetting-up phase & $t_{\mathrm{sat}} \leq t_{\mathrm{shw}}$ & None \\
\hline & & $\left\langle\bar{P}_{v}^{\prime} S_{c} / \bar{E}_{r}^{\prime}\left\{1-\left[1-\left(\bar{E}_{r}^{\prime} / \bar{P}_{v}^{\prime} S_{c}\right) C_{\mathrm{wi}}\right] e^{\bar{E}_{r}^{\prime} t_{\mathrm{shw}} / S_{c}}\right\} t_{\mathrm{sat}}>t_{\mathrm{shw}}\right.$ & \\
\hline$I_{w}$ & Interception during wetting-up phase & $\bar{P}_{v}^{\prime} \min \left(t_{\mathrm{sat}}, t_{\mathrm{shw}}\right)$ & $c P_{\text {sat }}-S_{c}$ \\
\hline$I_{s}$ & Interception during drying saturation phase & $\bar{E}_{r}^{\prime}\left(t_{\mathrm{shw}}-t_{\mathrm{sat}}\right)$ & $c \bar{E}^{\prime} / \bar{P}^{\prime}\left(P_{g}-P_{\mathrm{sat}}\right)$ \\
\hline$I_{d}$ & "Interception" during drying-out phase & None & $S_{c}$ \\
\hline$S_{f}$ & Precipitation diverted to stemflow & None & $c_{s} P_{g}$ \\
\hline$I_{t}$ & Stemflow & None & $\min \left(S_{f}, S_{t}\right)$ \\
\hline$I$ & Interception (storms not saturating canopy) & & $c P_{g}$ \\
\hline & Interception (storms saturating canopy) & $I_{w}+I_{s}$ & $I_{w}+I_{s}+I_{d}+I_{t}$ \\
\hline$C_{\mathrm{wd}}$ & Canopy water at end of drying-out phase & $C_{\mathrm{wf}}\left(e^{-E d \mathrm{drry}}\right.$ & None \\
\hline
\end{tabular}

drying-out phase is calculated by $C_{\mathrm{wd}}$, given $C_{\mathrm{wf}}$ and the mean evaporation rate during dry intervals $\left(\bar{E}_{d}^{\prime}\right)$. The value $C_{\mathrm{wd}}$ becomes $C_{\mathrm{wi}}$ at the beginning of the next shower, so that a running water balance is maintained over the entire simulation period.

We stipulated that the canopy was completely dry at the beginning of the simulation period (1 December), such that for the very first shower $C_{\mathrm{wi}}$ was equal to zero. Sufficient wetting and drying cycles occurred before the beginning of our first storm (7 December) that the initial condition of the canopy is of little consequence.

\section{c. Gash et al. (1995) model}

Gash (1979) simplified the Rutter model into a storm-based analytical model requiring only mean rainfall and evaporation rates, the temporal pattern of rainfall, and certain forest canopy parameters. The Gash (1979) model has been applied to various canopies and climates throughout the world (e.g., Pearce and Rowe 1981; Bruijnzeel and Wiersum 1987; Dolman 1987; Lloyd et al. 1988; Loustau et al. 1992; Návar et al. 1999). While the model performed well under these circumstances, Teklehaimanot et al. (1991) found it to be less accurate in stands where the canopy was sparse. Gash et al. (1995) updated the model to better account for such forests, validating the new formulas with a thin stand of maritime pine in France. Gash et al. (1995) suggested that the updated model (hereafter "the Gash model") be used in place of the original for all forest types. Carlyle-Moses and Price (1999) confirmed this recommendation by applying the model to hardwood stands in northern North America during the growing season.

Unlike the Mulder model, the Gash model does not maintain a running water balance between storms. Rather, the Gash model assumes that the canopy is completely dry before each storm. The Gash model does not distinguish between rainy and dry periods when calculating average evaporation, but instead takes storm-averaged values (denoted by an overbar). Stemflow is accounted for by the Gash model. The precipitation required to saturate the canopy $\left(P_{\text {sat }}\right)$ is a function of $\bar{P}^{\prime}$ and $\bar{E}^{\prime}$ (Table 3 ). If $P_{g}<P_{\text {sat }}$, the canopy fails to reach saturation and the total interception for the storm is $P_{v}$. For storms that saturate the canopy, the total interception is given by the sum of all four interception terms: $I_{w}, I_{s}, I_{d}$, and $I_{t}$, where $I_{d}$ represents the evaporation loss during the drying-out period between storms, which is essentially the remaining interception from the wetting-up period $\left(I_{w}\right) ; I_{t}$ is the stemflow, which is equal to the smaller of $S_{f}$ and $S_{t}$.

\section{d. WiMo model}

Herwitz and Slye (1995) recognized the effect of wind-driven precipitation on interception, a factor that neither the Gash nor the Mulder model takes into account. Hörmann et al. (1996) presented a model that does incorporate the influence wind-driven precipitation, named "WiMo." As described in that study, the WiMo model uses the same underlying equations as the Gash (1979) model, but adds the ability to vary $S_{c}$ with the maximum sustained wind speed during a rainstorm $\left(u_{\max }\right)$. Hörmann et al. (1996) found that WiMo proved more accurate than the Gash (1979) model for a beech forest in northern Germany.

We have updated the WiMo model's physics to match the equations in Gash et al. (1995), which are better optimized for our sparse canopy. The WiMo model calculates the $S_{c}$ for each storm as a function of $u_{\max }$ via a regression equation linking the optimum storage capacity $\left(S_{o}\right)$ and $u_{\max }$. We obtained $u_{\max }$ from our 5-min meteorological observations. To find the $S_{o}$ 
TABLE 4. Measured interception data as compared to the results from each model. Data for individual events are given as the percentage of $P_{g}$ intercepted. Differences are taken as the measured value minus the modeled value. The statistics for individual differences were calculated using the differences between the measured and modeled values in millimeters. The Nash-Sutcliffe model efficiency does not include the 9 February storm.

\begin{tabular}{|c|c|c|c|c|c|c|c|}
\hline & Measured & Mulder & Diff & Gash & Diff & WiMo & Diff \\
\hline \multicolumn{8}{|l|}{ Individual events } \\
\hline $7-8$ Dec 2004 & 8.9 & 10.0 & +1.1 & 10.0 & +1.1 & 4.9 & -4.0 \\
\hline 9-13 Dec 2004 & 9.2 & 8.0 & -1.2 & 6.7 & -2.5 & 6.5 & -2.7 \\
\hline 23-24 Dec 2004 & 6.0 & 5.6 & -0.4 & 6.3 & +0.3 & 8.0 & +2.0 \\
\hline 3-6 Jan 2005 & 5.2 & 9.8 & +5.6 & 7.2 & +2.0 & 7.3 & +2.1 \\
\hline 7-8 Jan 2005 & 4.6 & 10.0 & +5.4 & 10.0 & +5.4 & 4.9 & +0.3 \\
\hline 11-14 Jan 2005 & 5.6 & 3.7 & -1.9 & 3.1 & -2.5 & 5.3 & -0.3 \\
\hline 9-10 Feb 2005 & 49.9 & 10.0 & -39.9 & 10.0 & -39.9 & 10.0 & -39.9 \\
\hline 22-23 Mar 2005 & 4.4 & 6.9 & +2.5 & 4.4 & +0.0 & 5.8 & +1.4 \\
\hline 27-28 Mar 2005 & 5.2 & 6.0 & +0.8 & 3.3 & -1.9 & 4.8 & -0.4 \\
\hline 1-3 Apr 2005 & 1.9 & 3.3 & +1.4 & 2.7 & +0.8 & 2.2 & +0.3 \\
\hline 6-8 Apr 2005 & 2.2 & 10.0 & +7.8 & 10.0 & +7.8 & 10.0 & +7.8 \\
\hline \multicolumn{8}{|l|}{ For all events } \\
\hline Interception (mm) & 19.0 & 19.6 & +0.6 & 15.6 & -3.4 & 17.2 & -1.8 \\
\hline Error from measured (\%) & & & +3.2 & & -17.8 & & -9.5 \\
\hline Interception $\left(\%\right.$ of $\left.P_{G}\right)$ & 5.8 & 5.9 & +0.1 & 4.7 & -1.1 & 5.2 & -0.6 \\
\hline \multicolumn{8}{|l|}{ Statistics for individual differences } \\
\hline Standard deviation $(\mathrm{mm})$ & & 1.12 & & 1.03 & & 0.96 & \\
\hline Skewness & & -1.25 & & -1.06 & & -1.58 & \\
\hline Kurtosis & & 0.64 & & -0.05 & & 1.73 & \\
\hline Nash-Sutcliffe model efficiency & & 0.39 & & 0.50 & & 0.76 & \\
\hline
\end{tabular}

for each storm, WiMo employs a "bucket model" that calculates throughfall at each hourly time step $i\left(T_{f}^{i}\right)$ during the storm as

$$
T_{f}^{i}=\left\{\begin{array}{ccc}
c_{t} P_{g}^{i} & \text { if } & C_{w}^{i} \leq S_{c} \\
c_{t} P_{g}^{i}+C_{w}^{i}-S_{c} & \text { if } & C_{w}^{i}>S_{c}
\end{array},\right.
$$

where $C_{w}^{i}$ is

$$
C_{w}^{i}=C_{w}^{i-1}+P_{v}^{i}-E^{\prime i} .
$$

If $C_{w}^{i}$ exceeds $S_{c}$, it is reset to $S_{c}$ at the end of the time step, after the excess has been added to the throughfall term.

A computer program found $S_{o}$ for each storm by running the above bucket model for each $S_{c}$ between 0.1 and $4.0 \mathrm{~mm}$, in increments of $0.01 \mathrm{~mm}$. For each $S_{c}$, $T_{f}$ was compared against the measured value from our stand. The $S_{c}$ that produced the lowest absolute difference between $T_{f}$ and the measured value was judged to be the $S_{\mathrm{o}}$ for that storm. Ordered pairs of $S_{o}$ and $u_{\max }$ from each storm were used to generate a regression equation for $S_{c}$ as a function of $u_{\max }$.

\section{Results}

We derived a logarithmic regression equation $\left(\mathrm{r}^{2}=\right.$ $0.586, p<0.05)$ from the output of the WiMo bucket model:

$$
S_{c}=2.0677 \ln \left(u_{\max }\right)-2.3601 .
$$

The boundary conditions of this equation and its implications for the response of a leafless canopy to winddriven precipitation will be discussed in section 6 .

We obtained interception values from each model for each storm in Table 1. There is little explanation for the models' pattern of over- and underprediction for individual storms (Table 4). All three models twice overpredicted interception during high-volume events (22 March, 1 April), while underpredicting interception for two others (9 December, 11 January). During these four storms, the high precipitation rate quickly saturated the canopy, which remained saturated for the duration of the event. This reduced the total interception, as a saturated canopy can intercept at most the amount of water that evaporates from it, and during these storms $\bar{P}^{\prime}$ was much greater than $\bar{E}^{\prime}$. Similarly, the models both overpredicted (7 January) and underpredicted (9 February) interception for low-volume storms, in which the canopy was either slow to reach or never reached its storage capacity. No significant correlation was found between the models' differences for individual storms and any single meteorological variable in Table 1.

All models tended to overestimate interception during January, March, and April, while underestimating interception for the February storm and one of the De- 
cember storms (9 December). The models showed the greatest overestimates when the measured percentage of $P_{g}$ was low (3 January, 1 April, 6 April) and the greatest underestimates when the measured percentage was high (9 December, 9 February). These overestimates and underestimates indicate a lack of flexibility in each model, which will be discussed further in section 6.

We define $P_{G}$ to be the total precipitation summed over all 11 storms (i.e., $\Sigma P_{g}$ ). To evaluate each model's overall performance, we calculated 1) the total interception over the study period for models and measurements; 2) the percent error from the total measured interception; 3) the percentage of $P_{G}$ intercepted; and 4) the difference in this percentage between measured and modeled values. We also calculated the percentage of $P_{g}$ intercepted for each storm and computed the difference between measured and modeled values. We used the difference (in millimeters) between measured and modeled values for each storm to calculate the standard deviation, skewness, kurtosis, and NashSutcliffe model efficiency (Nash and Sutcliffe 1970) (Table 4). A normal Gaussian distribution was assumed to have a kurtosis of zero. The Nash-Sutcliffe efficiency does not include the 9 February storm. The models performed equally poorly for this storm and its inclusion would have resulted in negative Nash-Sutcliffe model efficiencies for all models. Removing this storm adds an equal amount to each model's efficiency value.

The Mulder model was the most accurate in terms of the total interception, overestimating the measured value by only $3.2 \%$. The WiMo model underestimated the total measured value by $9.5 \%$. The Gash model lagged the other two, underestimating the total measured interception by $17.8 \%$. All models predicted the percentage of $P_{G}$ intercepted to within $1.1 \%$ of $P_{G}$ of the measured value $(5.7 \%)$. Each model's differences formed a negatively skewed distribution, due to the 9 February outlier. It is interesting to note that while the Mulder model was the most accurate overall, it had the highest standard deviation, the lowest skewness, and a low kurtosis for its differences for individual storms. The Mulder model also had the lowest Nash-Sutcliffe model efficiency. These statistics imply that the Mulder model's differences for individual storms were typically larger than the other two models' differences.

When running sums of interceptions were considered, the models tracked the measured values relatively well (Fig. 2). The models oscillated between overestimating the measured running total during late December and January and underestimating it during February and March. It was only in April that the models converged toward to the measured total.

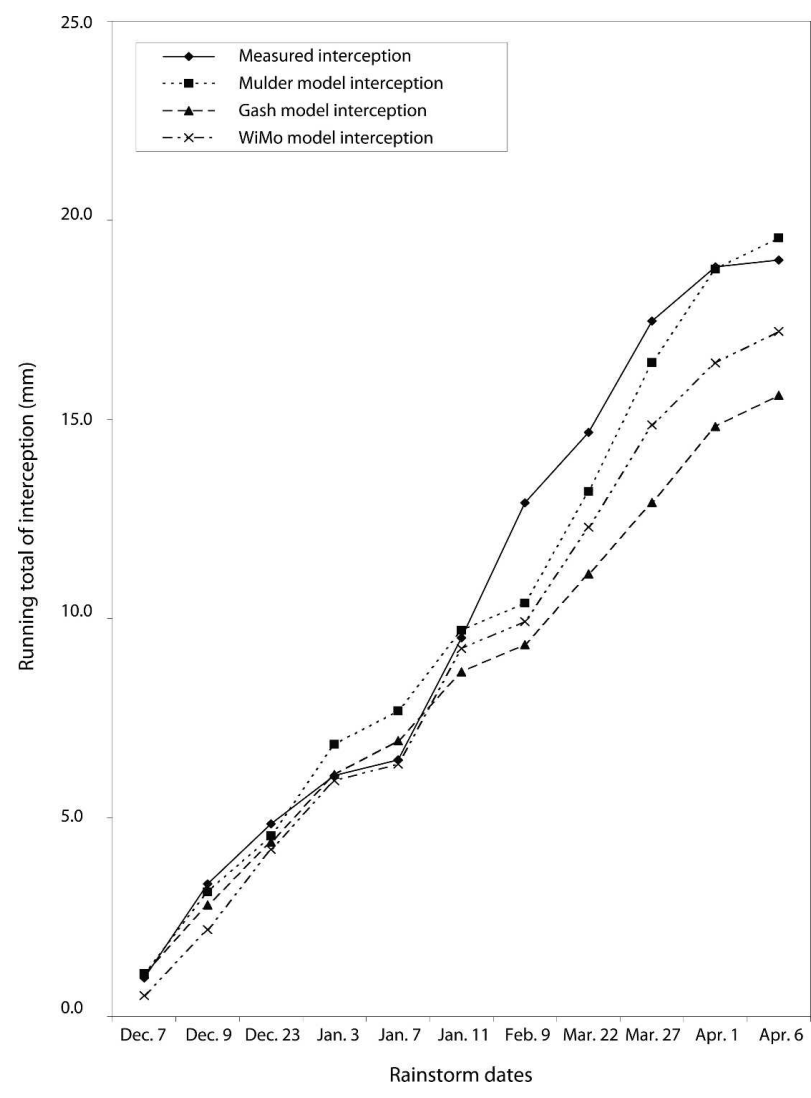

FIG. 2. Cumulative totals of measured and modeled interception $(\mathrm{mm})$ through the study period.

In section $3 \mathrm{~d}$, we noted that some of our stand and canopy parameters were adapted from previous studies. While we believe that these parameters are valid for our stand, we conducted a sensitivity analysis to examine whether the assumed parameter values had affected the models' estimates. We conducted additional runs of each model with modified values of each parameter that was inferred or derived from a previous study. The modified values represent the bounds of a reasonable error range for the parameter in question. The parameters in the Penman-Monteith equation were multiplied and divided by 2 , as were the stemflow parameters $c_{s}$ and $S_{t} ; S_{c}\left(c_{t}\right)$ was modified by adding or subtracting 0.5 (0.05). Only one parameter was changed at a time, as nonlinear interactions between parameters were estimated to be negligible.

The results of the sensitivity analysis are expressed as a ratio (Table 5),

$$
F=I_{\text {new }} / I
$$

where $F$ is the ratio, $I_{\text {new }}$ is the total interception after the modification, and $I$ is the total interception before the modification. All three models were most sensitive 
TABLE 5. A sensitivity test for the three models used in this study. All values are given as ratios of calculated interception. A ratio of 1.000 indicates that the model is perfectly insensitive to the given change in the given parameter. Parameters that do not apply to a model are marked $\mathrm{n} / \mathrm{a}$.

\begin{tabular}{|c|c|c|c|c|c|}
\hline Parameter & $\begin{array}{c}\text { Old } \\
\text { value }\end{array}$ & $\begin{array}{l}\text { New } \\
\text { value }\end{array}$ & Mulder & Gash & WiMo \\
\hline \multirow[t]{2}{*}{$S_{c}$} & \multirow[t]{2}{*}{$1.48 \mathrm{~mm}$} & $1.98 \mathrm{~mm}$ & 1.104 & 1.217 & $\mathrm{n} / \mathrm{a}$ \\
\hline & & $0.98 \mathrm{~mm}$ & 0.879 & 0.780 & $\mathrm{n} / \mathrm{a}$ \\
\hline \multirow[t]{2}{*}{$c_{t}$} & \multirow[t]{2}{*}{0.9} & 0.95 & 0.682 & 0.775 & 0.813 \\
\hline & & 0.85 & 1.133 & 1.152 & 1.089 \\
\hline \multirow[t]{2}{*}{$z$} & \multirow[t]{2}{*}{$30 \mathrm{~m}$} & $60 \mathrm{~m}$ & 1.002 & 1.000 & 1.000 \\
\hline & & $15 \mathrm{~m}$ & 0.976 & 0.997 & 0.998 \\
\hline \multirow[t]{2}{*}{$z_{0, H}$} & \multirow[t]{2}{*}{$0.24 \mathrm{~m}$} & $0.48 \mathrm{~m}$ & 1.001 & 1.001 & 1.001 \\
\hline & & $0.12 \mathrm{~m}$ & 0.999 & 1.000 & 1.000 \\
\hline \multirow[t]{2}{*}{$z_{0, M}$} & \multirow[t]{2}{*}{$1.74 \mathrm{~m}$} & $3.48 \mathrm{~m}$ & 1.005 & 1.001 & 1.001 \\
\hline & & $0.87 \mathrm{~m}$ & 0.998 & 1.000 & 1.000 \\
\hline \multirow[t]{2}{*}{$d$} & \multirow[t]{2}{*}{$12.8 \mathrm{~m}$} & $25.6 \mathrm{~m}$ & 0.982 & 0.998 & 0.998 \\
\hline & & $6.4 \mathrm{~m}$ & 0.999 & 1.000 & 1.000 \\
\hline \multirow[t]{2}{*}{$c_{s}$} & \multirow[t]{2}{*}{0.08} & 0.16 & $\mathrm{n} / \mathrm{a}$ & 1.000 & 1.000 \\
\hline & & 0.04 & $\mathrm{n} / \mathrm{a}$ & 1.000 & 1.000 \\
\hline \multirow[t]{2}{*}{$S_{t}$} & \multirow[t]{2}{*}{$0.09 \mathrm{~mm}$} & $0.18 \mathrm{~mm}$ & $\mathrm{n} / \mathrm{a}$ & 1.040 & 1.048 \\
\hline & & $0.04 \mathrm{~mm}$ & $\mathrm{n} / \mathrm{a}$ & 0.979 & 0.977 \\
\hline \multirow{2}{*}{$\begin{array}{c}\Delta t \text { between } \\
\text { showers }\end{array}$} & \multirow[t]{2}{*}{$2 \mathrm{~h}$} & $4 \mathrm{~h}$ & 0.983 & $\mathrm{n} / \mathrm{a}$ & $\mathrm{n} / \mathrm{a}$ \\
\hline & & $1 \mathrm{~h}$ & 1.006 & $\mathrm{n} / \mathrm{a}$ & $\mathrm{n} / \mathrm{a}$ \\
\hline
\end{tabular}

to changes in $c_{t}$. The WiMo model was not tested for changes in $S_{c}$ because the model calculates $S_{c}$ itself. The Gash and WiMo models showed no sensitivity to changes to $c_{s}$ because all rainstorms provided sufficient precipitation to saturate the trunks even at half of our original value of $c_{s}$, leaving stemflow to equal $S_{t}$ (Table 3).

We note that changes to individual evaporation parameters had little or no effect on the models' estimates of total interception. Therefore, the differences between measured and modeled values (Table 4) are not due to our assumed values for the evaporation parameters. The models were more sensitive to changes in $S_{c}$ and $c_{t}$. Our values for these two parameters are potentially a significant source of error. We continue to believe that the values specified for $S_{c}$ and $c_{t}$ are appropriate for our canopy, for the reasons given in section $3 \mathrm{~d}$.

\section{Discussion}

A mixed deciduous forest is naturally more susceptible to small-scale variations in throughfall than a homogeneous stand (Jackson 1971; Lloyd and Marques 1988; Lloyd et al. 1988). Throughfall can vary across a mixed stand by a considerable percentage of $P_{g}$, particularly for small storms, and this must be taken into account when model predictions are compared against "actual" values (Lloyd and Marques 1988; Carlyle-
Moses et al. 2004). While we randomly redistributed the throughfall gauges in the plot after each rainstorm to minimize any spatial throughfall variability, our gauges covered less than $1 \%$ of the stand area. Lloyd and Marques (1988) defined the probable standard error of estimating throughfall using this roving gauge method as

$$
\sigma=\sigma_{i}\left\{1+[N /(n m)]^{1 / 2}\right\},
$$

where $\sigma$ is the probable standard error of the measured values as a percentage of $P_{G}, \sigma_{i}$ is the standard error of the measured values as a percentage of $P_{G}, N$ is the total number of sampling points (304), $n$ is the number of gauges (30), and $m$ is the number of times the gauges were relocated (11). The probable standard error for this study is $8.1 \%$ of $P_{G}$, which is abnormally high due to the 9 February event; without this event $\sigma$ would be $4.1 \%$ of $P_{G}$, which agrees with the values given in Lloyd and Marques (1988) and Bryant et al. (2005). All three models' predictions of the percentage of $P_{G}$ intercepted (Table 4) are within the probable standard error of our measurements.

Our stemflow measurements represent an additional source of measurement error. We measured stemflow from only one tree in the plot. This tree had a height and dbh near the stand average and was of the same species (American beech) as the majority of canopy trees. While one tree represents the smallest of samples, stemflow is not a critical component of interception in our stand. Kittredge (1948) and Hörmann et al. (1996) agree that the percentage of $P_{g}$ diverted to stemflow in a beech forest is at most $10 \%$. Kittredge (1948) found that for a storm with a $P_{g}$ of $12 \mathrm{~mm}$, only $7.5 \%$ became stemflow. Over all 11 storms, measured stemflow in our stand was $5 \%$ of $P_{G}$. While we acknowledge that our limited sample of one tree cannot properly represent the variability in stemflow across the stand, that variability is almost certainly a negligible portion of interception in this stand.

The discrepancies between the models' predictions of interception must be a direct result of each model's basic assumptions. The WiMo model uses the same underlying equations as the Gash model, yet it provided a more accurate estimate of the total interception. It is highly probable that this advantage is due to the WiMo's ability to vary $S_{c}$ with $u_{\max }$. Whereas Hörmann et al. (1996) found that an increase in $u_{\max }$ caused a decrease in $\mathrm{S}_{c}$, our study found that $S_{c}$ increased logarithmically with $u_{\max }$ [Eq. (10)]. Hörmann et al. (1996) attributed their decrease in $S_{c}$ to stronger winds shaking more water from the canopy leaves, an effect that is not present in our leafless stand. Instead, we believe that as 
$u_{\max }$ increases, precipitation falls at a lower angle relative to the horizontal, increasing the effective canopy area and allowing the canopy to intercept a greater percentage of the $P_{g}$ (Herwitz and Slye 1995). Theoretically, the wind effects should be represented as an increased value of $c$ (decreased value of $c_{t}$ ). The WiMo model varies $S_{c}$, not $c$, with $u_{\max }$, and so the WiMo model represents the effect of wind speed on interception as an increased value of $S_{c}$ for a constant $c$. The logarithmic relationship between $S_{c}$ and $u_{\max }$ is physically reasonable: At low (high) wind speeds, a small increase in the wind speed will have a large (negligible) effect on the angle at which the rain falls relative to the horizontal.

The regression equation relating $S_{c}$ and $u_{\max }$ has a nonsensible boundary condition, as $S_{c}$ is negative for storms with $u_{\max }$ less than $3.1 \mathrm{~m} \mathrm{~s}^{-1}$. None of the 11 storms considered had a $u_{\max }$ below $3.1 \mathrm{~m} \mathrm{~s}^{-1}$, and so the regression equation in the Hörmann et al. (1996) bucket model fails to properly account for them. Hörmann et al. (1996) experienced similar problems, as their $S_{c}$ grew improbably large for low values of $u_{\max }$. Evidently, storms with $u_{\max }$ less than $3.1 \mathrm{~m} \mathrm{~s}^{-1}$ are quite rare in this stand during the leafless season, and so this boundary condition is not of great concern.

The Mulder model predicted the total interception more accurately than either the Gash or the WiMo model, and so might be considered the best interception model for this canopy under these conditions. While Mulder (1985) provides a different parameterization than Gash et al. (1995), it is also important to note that the Mulder model maintains a running water balance between storms, while the Gash and WiMo models do not. It is possible that the Gash and WiMo models' assumption that the canopy is always completely dry prior to each storm is not valid in this stand. An experiment that compared these models' performance for a set of storms that occurred immediately after one another, such that the canopy would not have the opportunity to dry, would highlight the effects of this assumption.

While all three models predicted the percentage of $P_{G}$ intercepted to within $1.1 \%$ of $P_{G}$ of the measured value, it may be that their accuracy can be attributed to the particular set of rainstorms in this study. The models frequently overestimated or underestimated interception for individual events (Table 4). Only 23 December, 27 March, and 1 April were predicted with any real accuracy. The standard deviation of each model's differences for individual storms is approximately 1 $\mathrm{mm}$. This is quite high considering that the least accurate model overall (the Gash model) underestimated the total precipitation by only $3.4 \mathrm{~mm}$. The WiMo model had the lowest standard deviation and the highest kurtosis value. These statistics indicate that the distribution of the WiMo model's differences had a higher peak around zero, where zero is the measured value. The Mulder and Gash models' differences, however, were more uniformly distributed across their space. The WiMo model also had the highest Nash-Sutcliffe model efficiency. The Nash-Sutcliffe efficiency compares the variance of the residuals (i.e., the variance of the difference between measured and modeled values) against the initial variance of the measured values. An efficiency score of unity represents identical measured and modeled values. A high score for the WiMo model indicates that the WiMo model's estimates for individual storms were, when considered together, reasonably close to the measured values. The Mulder model had the lowest Nash-Sutcliffe efficiency, the highest standard deviation, and a low kurtosis. These metrics imply that the Mulder model's accurate estimate of the total interception was a result of the offsetting of its inaccuracies for individual storms over the course of the study.

The WiMo model's ability to optimize $S_{c}$ improves its predictions of interception, both for individual storms and the seasonal total, but restricts its use in stands where wind measurements are difficult to obtain. The WiMo model thus represents a definite improvement over the Gash model in this stand, but its applicability to other leafless stands is predicated upon the availability of wind data and the determination of a suitable regression equation between $S_{c}$ and $u_{\max }$.

As mentioned previously, the measured percentage of $P_{g}$ intercepted varied greatly from storm to storm. The models overpredicted interception when this percentage was much lower than the fraction of canopy covered $(c)$ and underpredicted interception when the percentage was much higher than $c$. Over all 11 storms, the canopy intercepted $5.8 \%$ of $P_{G}$, which is lower than $c(10 \%)$ and closer to the models' predictions. (The canopy should intercept somewhat less than $c$, since the canopy does not intercept all incident precipitation while saturated.) In other words, the percentage of $P_{g}$ intercepted converged to a value less than $c$ over the course of the study period. This is evident from Fig. 2. The fixed coefficient of free throughfall $\left(c_{t}\right)$-and consequently $c$ [Eq. (4)]—constrained the models' ability to accurately determine interception during storms such as 9 February, as the modeled canopy could not possibly intercept more precipitation than the models allowed to strike it [Eq. (5)]. The $c_{t}$ establishes a hard upper boundary on interception in all three models. This limit does not exist in reality, as wind-driven events can increase the effective canopy area and allow 
the canopy to intercept more than $P_{v}$ (Herwitz and Slye 1995).

The models accurately predicted the total interception over the study period, but not the interception for the individual storms. The key difference between the total interception and the individual storms is that the measured percentage of $P_{g}$ intercepted was less than (greater than) $c$ for the total interception (individual storms). The percentage of $P_{G}$ intercepted is the critical value here, since these models are most often used to estimate interception over an entire season rather than for a single storm. Since all three models predicted the percentage of $P_{G}$ intercepted to within the probable standard error of the measurements, we believe that all three models will perform adequately for a leafless stand of this type in this climate, as long as $c_{t}$ is appropriately specified.

\section{Conclusions}

This study compared the Mulder (1985), Gash et al. (1995), and WiMo (Hörmann et al. 1996) interception models for a leafless mixed deciduous forest in the eastern United States. Each model predicted interception for 11 rainstorms during the winter and early spring of 2004/05. These values were compared against measurements collected approximately $2 \mathrm{~h}$ after each storm.

All three models demonstrated large differences for individual storms (Table 4) that bore no relationship to any applicable meteorological variable (Table 1), but were connected to the measured percentage of $P_{g}$ intercepted. The models underestimated interception when the percentage of $P_{g}$ intercepted was much greater than the canopy cover $c(10 \%)$ and overestimated interception when the percentage of $P_{g}$ was much less than $c$. While the percentage of $P_{g}$ intercepted varied for individual events-leading to the models' differences-it converged to a value less than $c$ as the sample size of storms grew, which allowed the models to accurately predict the total measured interception. This underscores the importance of selecting an appropriate value of $c$ (or $c_{t}$ ) for these models.

The Mulder model overestimated the measured percentage of $P_{G}$ intercepted by $0.1 \%$ of $P_{G}$; the WiMo model underestimated the measured percentage by $0.6 \%$ of $P_{G}$; and the Gash model underestimated by $1.1 \%$ of $P_{G}$. The WiMo model's advantage over the Gash model is most likely due to the former's ability to optimize the canopy storage capacity for the maximum sustained wind speed during a storm. In this stand, the storage capacity increased logarithmically with the maximum wind speed. The Mulder model gives the most accurate value of total interception, although its high standard deviation and low kurtosis imply that it was less accurate for individual storms. We hypothesize that the Mulder model's accuracy is due at least in part to its ability to maintain a moist canopy between storms.

Despite differences in underlying assumptions and complexity, each model successfully predicted the percentage of $P_{G}$ intercepted to within the probable standard error of our measurements. We therefore conclude that all three models are appropriate for use in predicting leafless-season interception in deciduous forests in the eastern United States.

Acknowledgments. The authors thank the Maryland Department of Natural Resources for permission to conduct the study on their property and the Delaware Environmental Observing System (DEOS) for providing the meteorological monitoring equipment. Kevin Brinson assisted us in collecting and formatting the meteorological data. The Maryland State Climatologist's Office (http://www.atmos.umd.edu/ climate) provided climate data for a location near the Fair Hill Natural Resource Management Area. We would also like to thank our three anonymous reviewers for their comments and suggestions.

\section{REFERENCES}

Abrahams, A. D., A. J. Parsons, and J. Wainwright, 2003: Disposition of rainwater under creosote-bush. Hydrol. Processes, 17, 2555-2566.

Bruijnzeel, L. A., and K. F. Wiersum, 1987: Rainfall interception by a young Acacia auriculiformis (A. Cunn) plantation forest in West Java, Indonesia: Application of Gash's analytical model. Hydrol. Processes, 1, 309-319.

Bryant, M. L., S. Bhat, and J. M. Jacobs, 2005: Measurements and modeling of throughfall variability for five forest communities in the southeastern US. J. Hydrol., 312, 95-108.

Calder, I. R., 1976: The measurement of water losses from a forested area using a "natural" lysismeter. J. Hydrol., 30, 311325 .

_- 1977: A model of transpiration and interception loss from a spruce forest in Plynlimon, central Wales. J. Hydrol., 33, 247265.

_ 1990: Evaporation in the Uplands. Wiley, $148 \mathrm{pp}$.

Carlyle-Moses, D. E., and A. G. Price, 1999: An evaluation of the Gash interception model in a northern hardwood stand. J. Hydrol., 214, 103-110.

— J. S. Flores Laureano, and A. G. Price, 2004: Throughfall and throughfall spatial variability in Madrean oak forest communities of northeastern Mexico. J. Hydrol., 297, 124-135.

Delage, Y., P. A. Bartlett, and J. H. McCaughey, 2002: Study of "soft" night-time surface-layer decoupling over forest canopies in a land-surface model. Bound.-Layer Meteor., 103, 253-276.

Derbyshire, S. H., 1999: Boundary-layer decoupling over cold surfaces as a physical boundary-instability. Bound.-Layer Meteor., 90, 297-325. 
Dolman, A. J., 1987: Summer and winter rainfall interception in an oak forest: Predictions with an analytical and a numerical simulation model. J. Hydrol., 90, 1-9.

Domingo, F., G. Sanchez, M. J. Moro, A. J. Brenner, and J. Puigdefabregas, 1998: Measurement and modelling of rainfall interception by three semi-arid canopies. Agric. For. Meteor., 91, 275-292.

Garratt, J. R., and R. J. Francey, 1978: Bulk characteristics of heat transfer in the baroclinic atmospheric boundary layer. Bound.-Layer Meteor., 15, 399-421.

Gash, J. H. C., 1979: An analytical model of rainfall interception by forests. Quart. J. Roy. Meteor. Soc., 105, 43-55.

— C. R. Lloyd, and G. Lachaud, 1995: Estimating sparse forest rainfall interception with an analytical model. J. Hydrol., 170, $79-86$.

Halldin, S., B. Saugier, and J. Y. Pontailler, 1984: Evapotranspiration of a deciduous forest: Simulation using routine meteorological data. J. Hydrol., 75, 323-341.

Harwood, K. G., J. S. Gillon, A. Roberts, and H. Griffiths, 1999: Determinants of isotopic coupling $\mathrm{CO}_{2}$ and water vapour within a Quercus petraea forest canopy. Oecologia, 119, 109119

Herwitz, S. R., and R. E. Slye, 1995: Three-dimensional modeling of canopy tree interception of wind-driven rainfall. $J$. Hydrol., 168, 205-226.

Hörmann, G., A. Branding, T. Clemen, M. Herbst, A. Hinrichs, and F. Thamm, 1996: Calculation and simulation of wind controlled canopy interception of a beech forest in northern Germany. Agric. For. Meteor., 79, 131-148.

Hutjes, R. W. A., A. Wierda, and A. W. L. Veen, 1990: Rainfall interception in the Tai Forest, Ivory Coast: Application of two simulation models to a humid tropical system. J. Hydrol., 114, 259-275.

Jackson, I. J., 1971: Problems of throughfall and interception assessment under tropical forest. J. Hydrol., 12, 234-254.

Kittredge, J., 1948: Forest Influences. McGraw-Hill, 394 pp.

Kruijt, B., Y. Malhi, J. Lloyd, A. D. Nobre, A. C. Miranda, M. G. P. Pereira, A. Culf, and J. Grace, 2000: Turbulence statistics above and within two Amazon rain forest canopies. Bound.-Layer Meteor., 94, 297-331.

Lankreijer, H. J. M., M. J. Hendricks, and W. Klassen, 1993: A comparison of models simulating rainfall interception of forests. Agric. For. Meteor., 64, 187-199.

Levia, D. F., and E. E. Frost, 2003: A review and evaluation of stemflow literature in the hydrologic and biogeochemical cycles of forested and agricultural ecosystems. J. Hydrol., 274, 1-29.

Liu, S. G., 1997: A new model for the prediction of rainfall interception in forest canopies. Ecol. Modell., 99, 151-159.

_ of cypress wetlands and slash pine uplands in north-central Florida. J. Hydrol., 207, 32-41.

— 2001: Evaluation of the Liu model for predicting rainfall interception in forests world-wide. Hydrol. Processes, 15, 2341-2360.

Lloyd, C. R., and A. de O. Marques, 1988: Spatial variability of throughfall and stemflow measurements in Amazonian rainforest. Agric. For. Meteor., 42, 63-73.

— J. H. C. Gash, W. J. Shuttleworth, and A. de O. Marques, 1988: The measurement and modelling of rainfall interception by Amazonian rainforest. Agric. For. Meteor., 43, 277 294.

Loescher, H. W., J. S. Powers, and S. F. Oberbauer, 2002: Spatial variation of throughfall volume in an old-growth tropical wet forest, Costa Rica. J. Trop. Ecol., 18, 397-407.

Loustau, D., P. Berbigier, and A. Granier, 1992: Interception loss, throughfall, and stemflow in a maritime pine stand. II. An application of Gash's analytical model of interception. J. Hydrol., 138, 469-485.

Moore, K., D. R. Fitzjarrald, and R. K. Sakai, 1996: Seasonal variation in radiative and turbulent exchange at a deciduous forest in central Massachussetts. J. Appl. Meteor., 35, 122134.

Mulder, J. P. M., 1985: Simulating interception loss using standard meteorological data. The Forest-Atmosphere Interaction, B. Hutchison and B. Hicks, Eds., D. Reidel, 177-196.

Nash, J. E., and J. V. Sutcliffe, 1970: River flow forecasting through conceptual models. Part I: A discussion of principles. J. Hydrol., 10, 282-290.

Návar, J., D. Carlyle-Moses, and M. A. Martinez, 1999: Interception loss from the Tamaulipan matorral thornscrub of northeastern Mexico: An application of the Gash analytical interception model. J. Arid Environ., 41, 1-10.

Pearce, A. J., and L. K. Rowe, 1981: Rainfall interception in a multi-storied evergreen mixed forest: Estimates using Gash's analytical model. J. Hydrol., 49, 341-353.

Rutter, A. J., 1967: Evaporation in forests. Endeavour, 26, 39-43.

_ , K. A. Kershaw, P. C. Robbins, and A. J. Morton, 1971: A predictive model of rainfall interception in forests. I. Derivation of the model from observations in a plantation of Corsican pine. Agric. For. Meteor., 9, 367-384.

- A. J. Morton, and P. C. Robbins, 1975: A predictive model of rainfall interception in forests. II. Generalization of the model and comparison with observations in some coniferous and hardwood stands. J. Appl. Ecol., 12, 367-380.

Stewart, J. B., 1977: Evaporation from the wet canopy of a pine forest. Water Resour. Res., 13, 915-921.

, 1978: A micrometeorological investigation into factors controlling the evaporation from a forest. Ph.D. thesis, University of Reading, $211 \mathrm{pp}$.

Teklehaimanot, Z., P. G. Jarvis, and D. C. Ladger, 1991: Rainfall interception and boundary layer conductance in relation to tree spacing. J. Hydrol., 123, 261-278.

Thom, A. S., 1971: Momentum absorption by vegetation. Quart. J. Roy. Meteor. Soc., 97, 414-428.

Wei, X., S. Liu, and C. Wang, 2005: Hydrological processes in major types of Chinese forest. Hydrol. Processes, 19, 63-75.

Whelan, M. J., and J. M. Anderson, 1996: Modelling spatial patterns of throughfall and interception loss in a Norway spruce (Picea abies) plantation at the plot scale. J. Hydrol., 186, 335-354. 